\title{
Ply and interlaminar behaviours of 3D-printed continuous carbon fibre-reinforced thermoplastic laminates; effects of processing conditions and microstructure
}

\author{
M. Iragi ${ }^{1}$, C. Pascual-González ${ }^{2}$, A. Esnaola ${ }^{1}$, C. S. Lopes ${ }^{2}$, L. \\ Aretxabaleta $^{1}$ \\ ${ }^{1}$ Mondragon Unibertsitatea, C/Loramendi 4, 20500, Arrasate-Mondragon, Spain. \\ ${ }^{2}$ IMDEA Materials Institute, C/Eric Kandel 2, 28906, Getafe, Madrid, Spain.
}

\begin{abstract}
Taking advantage of an extended design and manufacturing space for composites, the technology of Fused Filament Fabrication (FFF) of continuous fibre-reinforced thermoplastics shows great potential for the production of the next generation of lightweight structural parts. This novel process is very much under development, and knowledge of the mechanical behaviour of the resulting 3D-printed materials is still limited. In this work, the intra- and inter-laminar behaviours of carbon fibre/polyamide printed laminates were extensively characterised to determine ply elastic and strength properties, as well as interface strength and fracture characteristics. Moreover, the effects of eventual production defects on these properties were analysed, putting in evidence some of the present shortcomings of the FFF process. Such defects include non-homogeneous fibre distribution, large amounts of intra- and interlaminar voids, and weak interlayer bonding, which are likely to be due to insufficient thermo-mechanical consolidation of the material during the FFF process, and have significant influence on the matrix-dominated mechanical properties. As a result, the transverse and interlaminar properties were found to be lower than those obtained through Hot Compression Moulding of an equivalent material. Besides highlighting possible process improvements, the mechanical characterisation carried out in this work promises a significant
\end{abstract}

*Corresponding author: miragi@mondragon.edu 
contribution to the abilities of designing and simulating general 3D-printed composite parts.

Keywords: Material Extrusion, continuous fibre-reinforced polymers, mechanical properties, fracture toughness, effects of defects

\section{Introduction}

The additive manufacturing of polymeric matrix composites has undergone considerable developments in recent years. This is mainly due to the ability of the process to produce final components using less steps than conventional manufacturing techniques, without the need for special tools and generating small amounts of waste material. The 3D-printing of composite materials, with the inclusion of fibres in the matrix, has substantially improved the mechanical properties, as well as the dimensional stability of the material during the process, allowing the production of larger parts [1, 2]. Due to the improved mechanical performance, in addition to prototyping, 3D-printing of composites is also suitable for manufacturing factory tools, spare parts and custom products. As a result, its use is increasing in sectors such as bio-medical, aerospace, automotive and industrial $[3,4]$. To date, discontinuous carbon or glass fibres have mainly been used to reinforce the polymer, but in recent years continuous fibre composite printers have been developed, which have significantly improved the mechanical performance and greatly expanded the field of application of 3D-printed polymers [1, 2].

Fused Filament Fabrication (FFF) is the most widespread 3D-printing technology due to the simplicity of the process, the low cost of the printers and the ability to combine different materials [4]. The FFF printing of continuous fibre-reinforced thermoplastics is based on two different systems for the impregnation of the fibre in the matrix [5]: the use of a pre-impregnated filament and the impregnation inside the extrusion head of the printer. The second system does not require a pre-extrusion process of the material, and is therefore more economical. In addition, it is possible to combine different materials and respective proportions in the same printer. However, preliminary researches have indicated that the mechanical properties obtained are lower than those used by the pre-impregnated filaments, due to insufficient matrix-fibre impregnation $[6,7]$.

One of the most promising possibilities offered by the technology of 3Dprinting of continuous fibre composites is its ability to steer fibres through 
curved tracks making it suitable for the manufacture of non-conventional laminates. An example of these types of laminates are variable stiffness panels, where the load redistribution can be used for stiffness design, increased resistance and improved stability against imperfections and geometric discontinuities [8]. Advanced numerical models based on advanced failure criteria and continuum damage mechanisms were developed for the design of these laminates, and were successfully tested on components manufactured by $\mathrm{Au}-$ tomated Fibre Placement (AFP) [9-11]. Although some preliminary studies have been carried out [12-14], the applicability of 3D-printing technology for the manufacture of non-conventional laminates is still to be developed. To design and manufacture these types of structures with 3D-printing, the printing process limitations and the mechanical behaviour of the printed materials must be known in depth.

In recent years, different studies have addressed the physical and mechanical characterisation of printed continuous carbon fibre-reinforced polymers (CCFRP) obtained with pre-impregnated filament FFF technology. Several publications analysed the microstructure of the printed composites as well as the deposition and filling limits of the printing process [15-17]. The mechanical characterisation of the printed CCFRP was also performed for different load cases: tension [15, 16, 18-20], compression [19], in-plane shear $[19,20]$ and interlaminar shear [21]. In other studies, the influence of the laminate sequence, the type and density of reinforcement and fill patterns on the tensile, compressive and bending behaviour of printed components were analysed [22-25]. There are also studies that analysed other phenomena such as creep [26], fatigue [27], quasi-static indentation [16], impact resistance [28] and hygromechanical behaviour [17]. In these studies it was observed that the mechanical behaviour of the printed materials was highly conditioned by process-induced defects.

The aforementioned studies are an important contribution to the development of this 3D-printing technology; however, there remains a lack of research into the mechanical characterisation of printed continuous fibre-reinforced thermoplastics. On the one hand, most of the published works have characterised the properties of the laminate obtained directly from the print, which includes contours and outer layers of non-reinforced material, and not the lamina properties of the printed CCFRP. Lamina properties are necessary for the general design and simulation of these laminated materials. To the knowledge of the authors, only one study determined the elastic properties at lamina level [20]. On the other hand, there are no published research 
on characterisation of interlaminar fracture behaviour of printed continuous fibre-reinforced thermoplastic laminates. This characterisation is necessary in order to apply delamination failure criteria for composite damage tolerance and durability analyses. Thus, there is a need for a detailed study that collects a complete mechanical characterisation of the material necessary to drive the use of this new technology in the design of complex and optimised composite parts.

In this study, the ply and interlaminar behaviours of a 3D-printed continuous carbon fibre-reinforced polyamide laminate are extensively characterised to determine elastic, strength and fracture properties, and to identify the most relevant fracture mechanisms. At the ply level, different material orthotropic directions are addressed, i.e. longitudinal, transverse and in-plane shear, as well as load cases (tension and compression). At interface level, interlaminar resistance and critical energy release rates under mode I and mode II loadings are investigated. In the discussion of the results obtained, these properties are compared to those of an equivalent material manufactured by means of Hot Compression Moulding [29-32] to assess the performance of this novel FFF process. In addition, the microstructure of the printed material and the thermal history of the material during the process have been studied to identify process-induced defects and measure their impact on the resulting mechanical properties.

\section{Printing process, material and test methods}

\subsection{Printing process and resulting material}

The printer employed in this study was the MarkTwo@ from Markforged $\mathrm{R}$, which uses pre-impregnated filament FFF 3D-printing technology [33]. This printer has two extrusion systems, one for printing construction material and another one for printing reinforcement material (Figure 1(a)). The head moves in the $x y$ plane during the printing of each layer, while the bed positions the part on the $z$-axis. The reinforced materials are polyamide (PA) based composites with continuous carbon, glass or aramid fibres. In this study, the layers were filled with continuous fibre-reinforced composite using a rectangular pattern with a 100\% filling density and a bead orientation that depends on the test configuration (Figure 1(b)). The construction material can be either neat polyamide 6 (PA6) or PA6 reinforced with short carbon fibre. Both are used for printing the first and last layers of a laminate 
(floor and roof layers, as shown on Figure 1(a)), and the contours of each layer (Figure 1(b)).

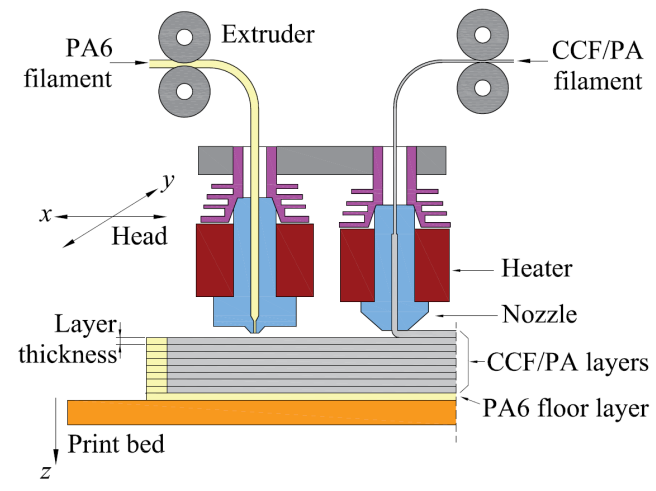

(a)

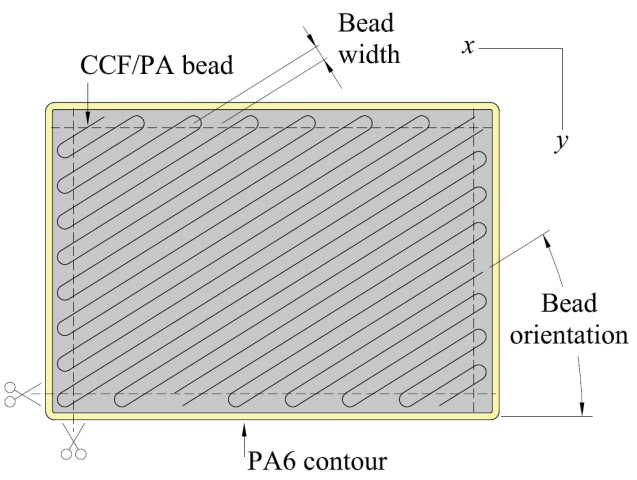

(b)

Figure 1: CCF/PA composite 3D-printing FFF system: (a) general drawing of the process and stacking sequence of the layers and (b) rectangular filling pattern of a layer.

The material characterised in this study was the continuous carbon fibrereinforced polyamide (CCF/PA). Carbon fibre-reinforced composites offer high mechanical properties and low density, and are widely used in sectors such as aerospace and automotive. In addition, thermoplastic matrix composites are of special interest because they do not require a curing stage, are easier to recycle than thermoset resins, and can be mass-produced [34]. The composition and calorimetric properties of all the filaments available in the MarkTwo@ printer were reported in [35] which states that the CCF/PA filament has an average diameter of $363 \mathrm{um}$ and contains approximately 1006 fibres of $7 \mu \mathrm{m}$ in diameter, resulting in a fibre volume fraction of $34 \%$. The results obtained in the calorimetry tests indicated that the PA matrix is amorphous and matches the profile of PA 6/3T.

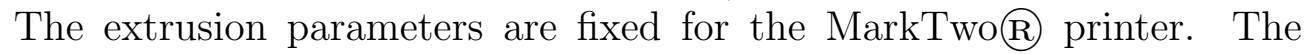
composite filament is extruded at a temperature of $252^{\circ} \mathrm{C}$ and at a speed of $15 \mathrm{~mm} / \mathrm{s}$. The layer thickness is $125 \mu \mathrm{m}$ (Figure 1(a)), therefore the $363 \mu \mathrm{m}$ diameter filament undergoes a considerable flattening during the printing process. The width of the printed bead is $0.9 \mathrm{~mm}$ (Figure 1(b)) which matches with the diameter of the printer nozzle.

The fibre and void contents of the printed CCF/PA composite were measured in accordance with ASTM D3171 by matrix digestion in sulphuric 
acid/hydrogen peroxide [36]. Three square samples with $25 \mathrm{~mm}$ sides and 2 $\mathrm{mm}$ thickness with a $[0]_{16}$ unidirectional laminate were analysed. For these specific tests, the floor and roof PA layers and PA contours were removed in order to determine the amount of fibre and voids of the CCF/PA composite.

Matrix digestion of each sample was carried out in $50 \mathrm{ml}$ of sulphuric acid, on a hot plate at $275^{\circ} \mathrm{C}$ for 5 hours. Then, $50 \mathrm{ml}$ of $30 \%$ hydrogen peroxide was added to oxidise the PA matrix. In order to determine the volumetric fibre and void contents the density was determined by weighing the samples in air and water, in accordance with the procedure described in ASTM D792 [37]. The density of the PA matrix and carbon fibre reinforcement were obtained from the literature [38, 39].

Table 1 compares the results obtained for the printed CCF/PA material and those for the pre-printed filaments [35]. Similar fibre contents were obtained using the matrix burn-off technique [18] and using microscope image processing technique [15]. The amount of voids is high compared to that of the pre-printed filament.

Table 1: Comparison of density, fibre content and voids content between the filament [35] and printed sample of CCF/PA (the standard deviation is indicated in parentheses).

\begin{tabular}{ccc}
\hline Property & Filament & Printed sample \\
\hline Density $\left(\mathrm{kg} / \mathrm{dm}^{3}\right)$ & 1.35 & $1.25(0.01)$ \\
Fibre volume fraction $\%$ & 33.9 & $31.4(0.1)$ \\
Voids volume fraction $\%$ & 0.2 & $7.5(0.3)$ \\
\hline
\end{tabular}

\subsection{Mechanical testing methods}

In order to characterise longitudinal and transverse ply properties, tensile and compressive mechanical tests were carried out in accordance with the ASTM D3039 [40] and ASTM D3410 [41] standards respectively. Tensile tests were performed on a Zwick/Roell universal testing machine equipped with a $50 \mathrm{kN}$ load cell and at a load-rate of $1.5 \mathrm{~mm} / \mathrm{min}$. Longitudinal and transverse strains were measured with a Gom-Aramis digital image correlation (DIC) system. In the case of compression tests, an Instron universal testing machine equipped with a $150 \mathrm{kN}$ load cell was used at a load-rate of $1.5 \mathrm{~mm} / \mathrm{min}$. The longitudinal strain of both sides was measured with strain gauges of a $3.18 \mathrm{~mm}$ sized active grid in order to determine the bending level in the test and the stiffness of the material. The characterisation of the inplane shear behaviour was carried out in compliance with the ASTM D3518 
standard by means of tensile testing of $[ \pm 45]_{4 \mathrm{~S}}$ laminates [42]. In this case, the load-rate was $5 \mathrm{~mm} / \mathrm{min}$.

The characterisation of the interlaminar shear strength was carried out by means of the short beam shear (SBS) test according to the ASTM D2344 standard [43]. The tests were performed in a Zwick/Roell universal testing machine equipped with a $5 \mathrm{kN}$ load cell at a $1 \mathrm{~mm} / \mathrm{min}$ load rate and $24 \mathrm{~mm}$ spam length.

The characterisations of mode I and mode II interlaminar fracture toughness were carried out using the double cantilever beam (DCB) and endnotched flexure (ENF) tests respectively, in accordance with the ASTM D5528 [44] and ASTM D7905 standards [45]. The DCB tests were performed on a Instron universal testing machine equipped with a $500 \mathrm{~N}$ load cell and at a load-rate of $1 \mathrm{~mm} / \mathrm{min}$. The pre-crack length was $50 \mathrm{~mm}$ and it propagated to $80 \mathrm{~mm}$ under crack-opening load. The ENF 3-point bending tests were performed on an Instron universal testing machine equipped with a $10 \mathrm{kN}$ load cell and at a $0.5 \mathrm{~mm} / \mathrm{min}$ load-rate. The nominal span and the average pre-crack length were $100 \mathrm{~mm}$ and $30 \mathrm{~mm}$, respectively. The typical fracture surfaces produced by the different test types were examined by scanning electron microscopy (FEI Nova NanoSEM 450) and optical macroscopy (Leica Z16 APO).

\subsection{Samples preparation}

The lay-up and dimensions of the samples for the different tests are given in Table 2. Five repetitions of each experiment were performed. All samples were obtained by cutting a multi-sample printed plate, thus also eliminating the PA contour (Figure 1(b)). A single layer of floor and roof of PA6 was used in the manufacture of the plates. In order to obtain the lamina properties of the $\mathrm{CCF} / \mathrm{PA}$ material exclusively, the results from the mechanical tests were recalculated, based on a rule of mixtures applied to two homogeneous materials, the PA6 of the outer layers and the CCF/PA of the inner layers. The mechanical specifications for printed PA6 were taken from literature [35]. 
Table 2: Standards carried out, lay-up (bead/fibre orientation and number of layers) and dimensions (thickness $\times$ width $\times$ length) of the tested samples.

\begin{tabular}{lccc}
\hline Test & ASTM & Lay-up & Dimensions $(\mathrm{mm})$ \\
\hline Longitudinal tension & D 3039 & {$[0]_{16}$} & $2.25 \times 15 \times 250$ \\
Longitudinal compression & D 3410 & {$[0]_{16}$} & $2.25 \times 12.5 \times 135$ \\
Transversal tension & D 3039 & {$[90]_{18}$} & $2.5 \times 22 \times 200$ \\
Transversal compression & D 3410 & {$[90]_{26}$} & $3.5 \times 20 \times 135$ \\
In-plane shear & D 3518 & {$[ \pm 45]_{4 \mathrm{~S}}$} & $2.25 \times 22 \times 210$ \\
Interlaminar shear & D 2344 & {$[0]_{46}$} & $6 \times 12 \times 40$ \\
Interlaminar fracture Mode I & D 5528 & {$[0]_{24}$} & $9 \times 25 \times 180$ \\
Interlaminar fracture Mode II & D 7905 & {$[0]_{24}$} & $9 \times 25 \times 130$ \\
\hline
\end{tabular}

Many of the tested samples required tabs to ensure proper load transfer. These tabs were manufactured separately by 3D-printing of continuous fibreglass composite and bonded with an epoxy adhesive (Loctiteß) EA 9466 ${ }^{\mathrm{TM}}$ ). Moreover, PA is a hygroscopic polymer and its mechanical properties depend on the quantity of absorbed moisture [17]. To ensure the same testing conditions in the different configurations, all the samples were conditioned in a climatic chamber for at least 4 days before testing at $23^{\circ} \mathrm{C}$ and $50 \%$ relative humidity.

The same samples were used for both mode I and mode II interlaminar fracture tests, i.e., the mode I crack was used as a pre-crack for mode II. Due to warping problems, it was not possible to print monolithic laminates thick enough to perform the test without fracture of the loading arms due to excessive bending deformation. For this reason, sandwich-type samples were manufactured, consisting of a core of printed $\mathrm{CCF} / \mathrm{PA}$ material of 3 mm thickness, reinforced on the top and bottom with unprinted composite skins of epoxy resin and weave fabric Dyneema(R) (Figure 2). This solution was previously implemented in [46] with successful results. To create the delamination initiator, the print was stopped during the printing process and the required area was covered with paper adhesive tape. 


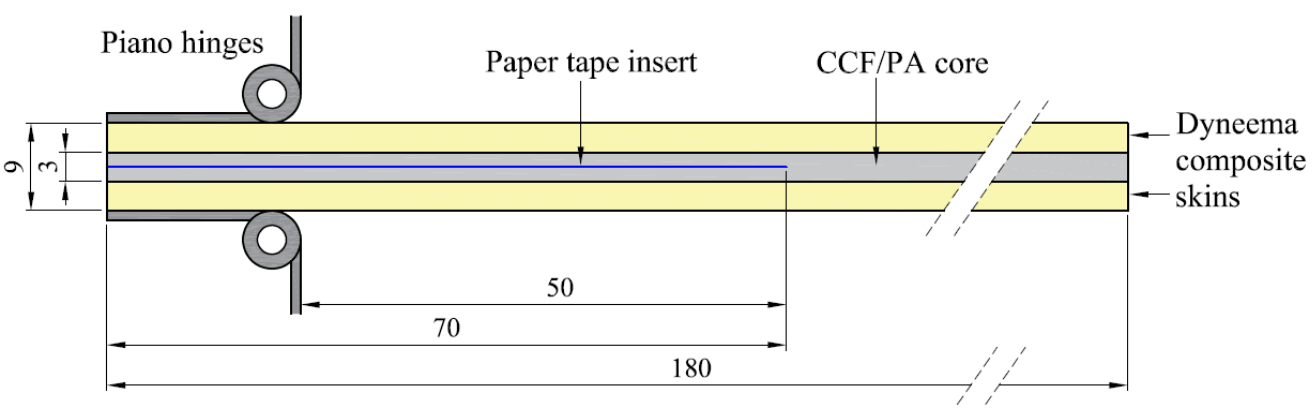

Figure 2: Interlaminar mode I fracture test sample reinforced with Dyneema@ composite skins.

\section{Results}

\subsection{Ply longitudinal behaviour}

The average measured mechanical values for longitudinal tensile and compressive tests are compiled in Table 3. For the longitudinal tensile tests, brittle fracture was observed at $1.27 \%$ strain (Figure 3(a)). The stress-strain behaviour is approximately linear-elastic, in spite of a slight stiffening effect which is characteristic of continuous carbon fibre-reinforced composites and is likely to be caused by the change of morphology of the fibres under increasing load, as discussed in [47]. The average values of initial tensile modulus $\left(E_{1}^{\mathrm{t}}\right.$ in Figure 3(a)) and of tensile strength were $69.4 \mathrm{GPa}$ and $905.3 \mathrm{MPa}$ respectively.

With regards to the fracture behaviours, a longitudinal splitting mode is observed, mainly between material beads and between individual layers (Figure 4(a)). The mechanisms of fibre breakage, fibre pull-out and matrix fracture can be observed from the SEM images of the fracture surface (Figures 4(b) and 4(c)). The pulled-out fibres have matrix residues on the surface (Figure 4(c)), which may indicate proper fibre/matrix interfacial bonding inside the beads. 


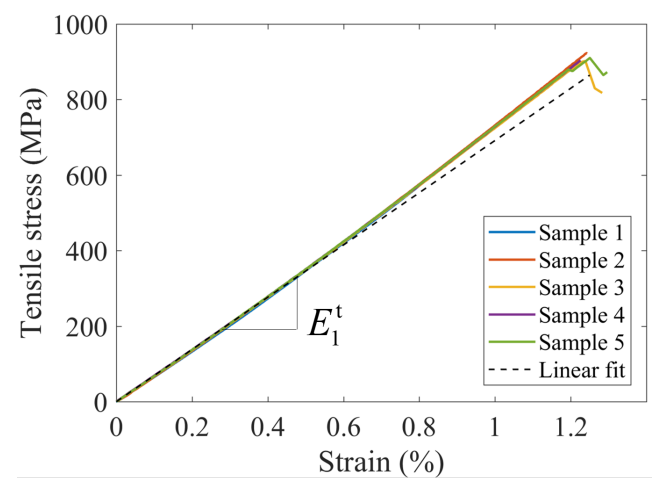

(a)

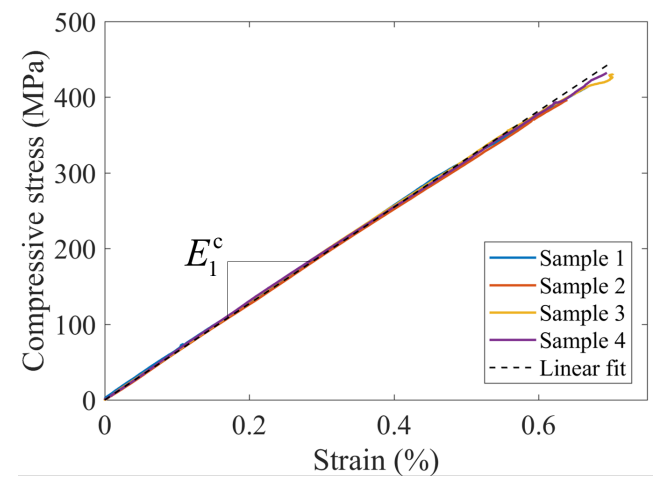

(b)

Figure 3: Stress-strain curves in longitudinal direction and average linear fit: (a) tensile behaviour and (b) compressive behaviour. The linear fitting was made in a strain range of $0.1-0.3 \%$.

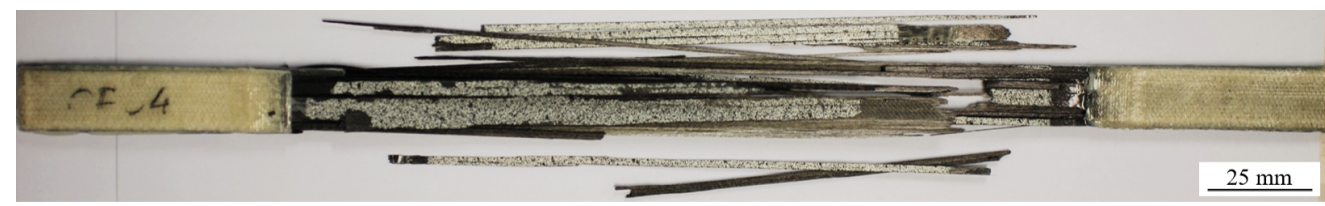

(a)

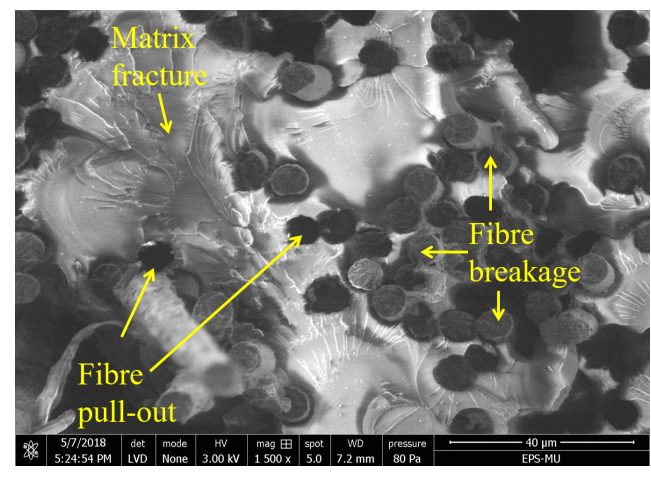

(b)

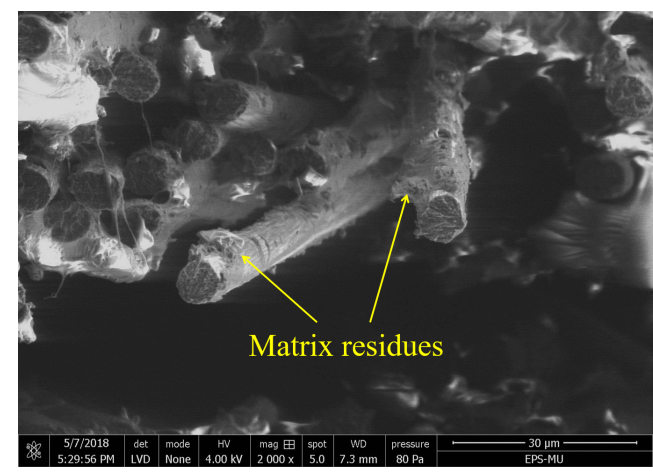

(c)

Figure 4: Longitudinal tensile fracture: (a) longitudinal splitting fracture mode, (b) fibre breakage, fibre pull-out mechanisms and matrix fracture in the fracture surface and (c) matrix residues on the surface of the pulled-out fibres.

The longitudinal compressive behaviour can be considered linear-elastic up to failure, with a maximum deformation of $0.69 \%$ (Figure $3(\mathrm{~b})$ ). The av- 


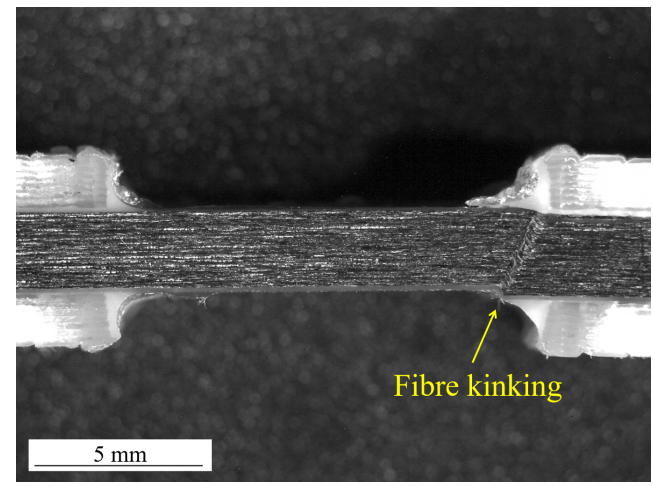

(a) $20^{\circ}\left(3^{\circ}\right)$, considering the average of 5 samples.

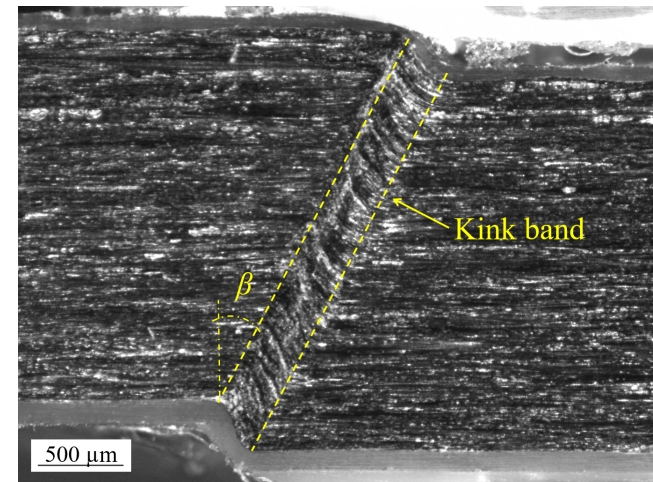

(b)

Figure 5: Macroscopic images of the side view of the longitudinal compression fracture: (a) fibre kinking mechanism near the tab and (b) fibre kinking band and inclination $\beta$.

erage values of compressive modulus $\left(E_{1}^{\mathrm{c}}\right.$ in Figure $\left.3(\mathrm{~b})\right)$ and of compressive strength were $63.9 \mathrm{GPa}$ and $426 \mathrm{MPa}$ respectively. Compared to tensile properties, compressive stiffness was slightly lower while the compressive strength was $47 \%$ of the tensile strength in absolute value.

Macroscopic images of the side view of the fractured sample are shown in Figure 5 for two different magnification levels. The fibre kinking mechanism is observed near the tab (Figure 5(a)) due to micro-buckling of the composite layers in a narrow band. The average inclination of the kink band, $\beta$, was

(a) fibre kinking mechanism near the tab and (b) fibre kinking band and inclination $\beta$.

The longitudinal tensile and compression properties are higher (about $16 \%$ ) than those reported by Markforged $\mathbb{R}$ [48]. This may be because Markforged $\mathrm{R}$ obtained the properties of the sandwich configuration (with internal $\mathrm{CCF} / \mathrm{PA}$ layers and external non-reinforced PA layers) and not that of the lamina.

\subsection{Ply transverse behaviour}

The stress-strain curves resulting from the transverse tension and compression test are plotted in Figure 6. The corresponding fracture images are shown in Figures 7 and 8. With regards to the transverse tensile behaviour, very low plastic strain was observed and the fracture can be considered to be brittle (Figure 6(a)). The average values of tensile modulus and tensile strength were $3.5 \mathrm{GPa}\left(E_{2}^{\mathrm{t}}\right.$ in Figure $\left.6(\mathrm{a})\right)$ and $17.9 \mathrm{MPa}$, respectively (see Table 3). 


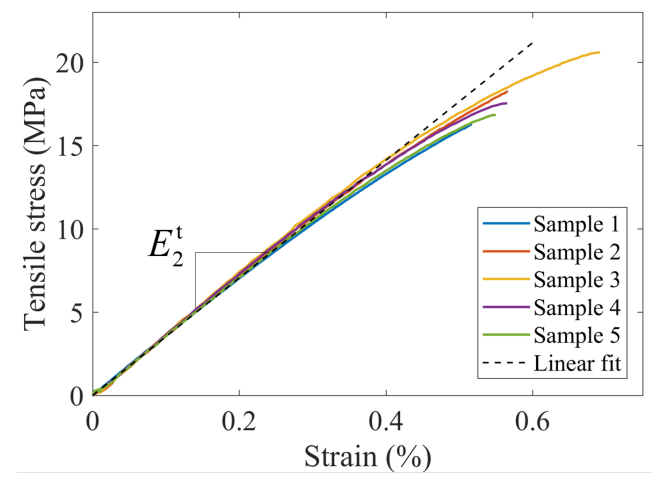

(a)

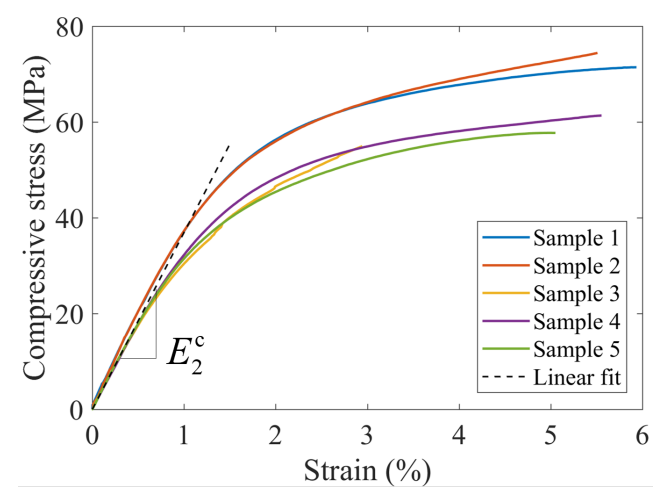

(b)

Figure 6: Stress-strain curves in transverse direction and average linear fit: (a) tensile behaviour and (b) compressive behaviour. The linear fitting was made in a strain range of $0.1-0.3 \%$. 


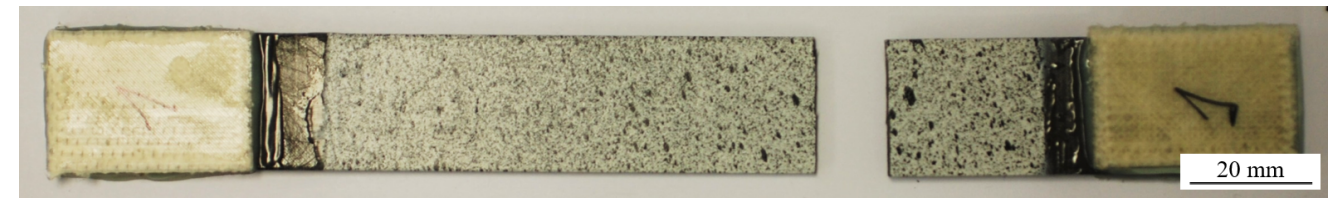

(a)

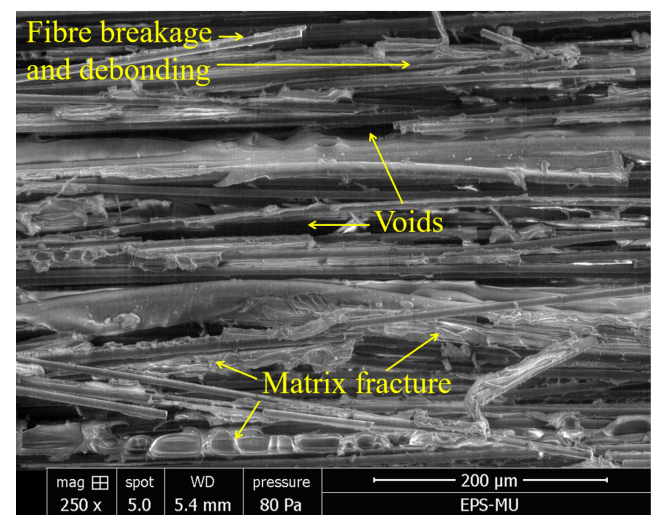

(b)

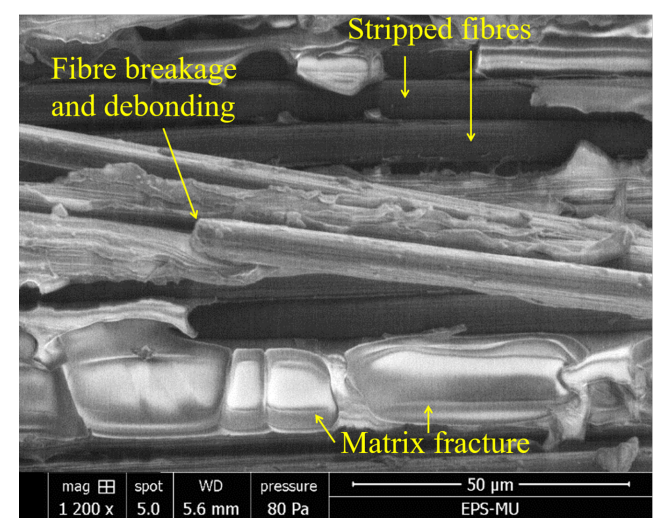

(c)

Figure 7: Transverse tensile fracture: (a) fracture plane perpendicular to the load, (b) and (c) SEM images of the fracture surface with two different magnification level. Matrix fracture zones, fibre breakage and debonding zones, voids and stripped fibres with very little impregnated resin are observed.

Under transverse compression, the material showed a more ductile behaviour and exceeded $5 \%$ strain before failure (Figure 6(b)). This effect may be due to the elasto-plastic behaviour of the PA matrix. The mechanical properties for compression show a greater dispersion than for tension (Table 3 and Figure 6(b)). The compression modulus $E_{2}^{\mathrm{C}}$ was $3.7 \mathrm{GPa}$, slightly higher than the tensile modulus, and the compressive strength was $66 \mathrm{MPa}$, more than three times the tensile strength, in absolute value. The failure mode was by micro-buckling of the composite layers forming $\mathrm{X}$ - or $\mathrm{V}$-shaped bands (Figure 8). Layer delamination and layer breakage zones were identified in these bands. The average inclination of the kink band $\beta$ was $43^{\circ}\left(8^{\circ}\right)$ taking into account the 5 samples. 


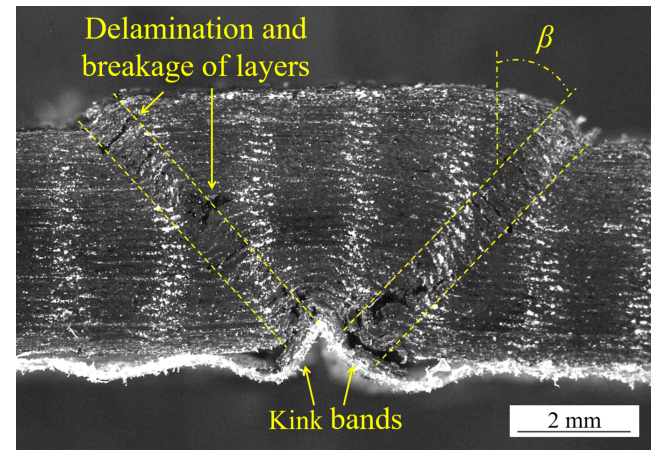

(a)

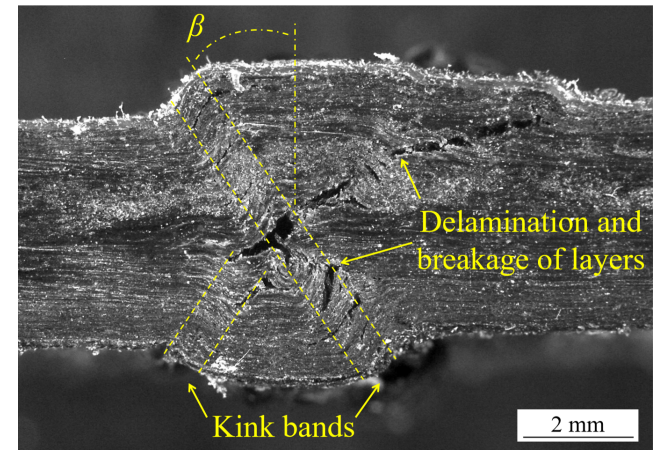

(b)

Figure 8: Macroscopic images of the side view of transverse compression fracture: (a) Vshaped kink bands and (b) X-shaped kink bands. Layer delamination and layer breakage zones are identified in these bands.

\subsection{In-plane shear behaviour}

Extremely high strains were achieved during the in-plane shear tests (Figures 9(a) and 9(b)). This may be due to the ductile nature of the PA matrix. For the highest applied strains, a stiffening effect can be appreciated. This is likely because of the alignment of the fibres to the load direction, as denoted by an inflexion point in the stress-strain behaviour. The in-plane shear strength of $61.5 \mathrm{MPa}$ was considered to occur just before the initiation of the fibre alignment phenomenon (the inflection point) which corresponded to a $25 \%$ shear strain level. The shear strength for a 5\% strain, as considered in the test standard, was also determined (Table 3). The shear modulus was 1.9 GPa $\left(G_{12}\right.$ in Figure $\left.9(\mathrm{~b})\right)$. From the obtained fracture surface, fibre breakage and pull-out, shearing of beads and inter-layer delamination can be observed (Figure 9(c)). 


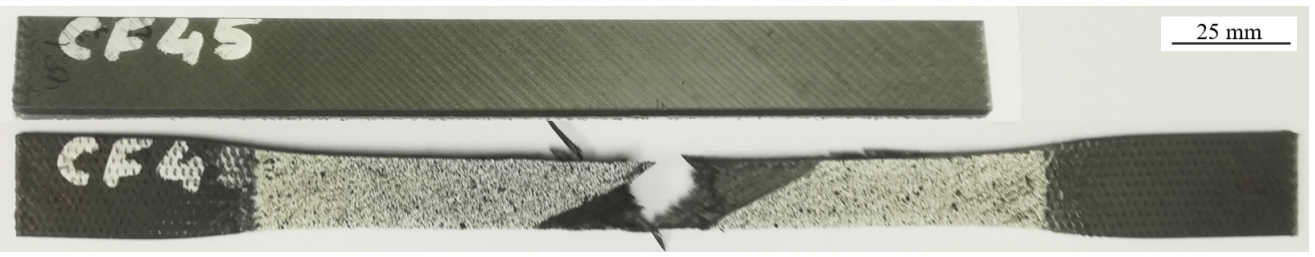

(a)

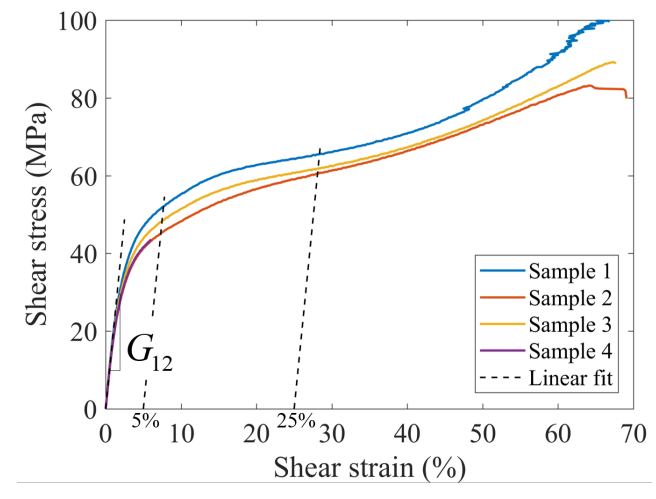

(b)

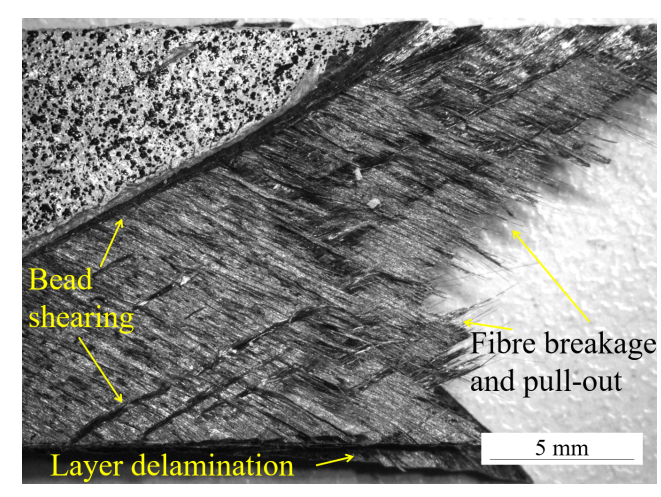

(c)

Figure 9: In-plane shear behaviour: (a) sample shape after and before the test, (b) shear stress-strain curves and average linear fit, and (c) macroscopic image of the fracture. Fibre breakage and pull-out, beads shearing and interlayer delamination fracture mechanisms are identified. The linear fitting was made between 0.2 and $0.6 \%$ shear strain.

\subsection{Interlaminar behaviour}

During the SBS tests small delaminations occurred between the load and support points in the area of maximum interlaminar shear stress (Figure 10(b)). Inelastic behaviour of the material was also observed, as indicated by the shape of the deformation (Figure 10(b)). The interlaminar shear strength was $37.9 \mathrm{MPa}$ on average (Table 3). 


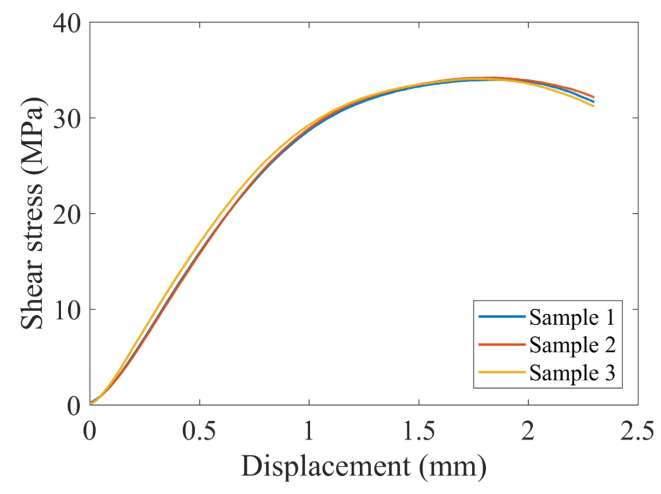

(a)

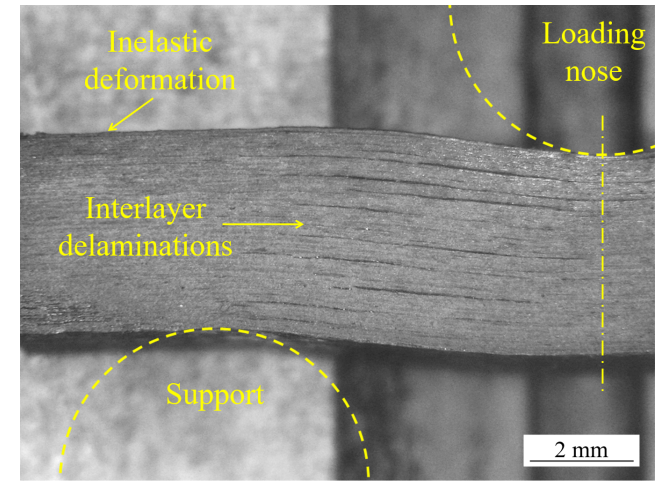

(b)

Figure 10: Interlaminar shear behaviour: (a) stress-displacement curves of the short-beam shear test and (b) macroscopic image of the side view of a fractured sample. Interlayer delaminations and inelastic deformation shape are identified.

The load-deflection curves of the DCB tests are shown in Figure 11(a). The load-deflection ratio is linear, with a slight deviation before fracture propagation. This behaviour is characteristic of tough matrix composites. In the propagation phase a great dispersion in the results is observed. The crack growth was stable throughout the entire test. The mode I interlaminar fracture toughness was calculated using the modified beam theory method given in ASTM D5528 [44]. A resistance-type fracture behaviour was identified (Figure 11(b)): the toughness increased in the fracture initiation phase and then tended to stabilise in the propagation phase. The cause of the increased delamination resistance could be the development of fibre bridging (Figure 12(a)). The mode I fracture toughness for a total crack length of $80 \mathrm{~mm}$ was $2(0.17) \mathrm{kJ} / \mathrm{m}^{2}$. The fracture surface is very irregular (Figure 12(b)). Debonded and fractured fibres are observed, which have probably formed bridges between the crack surfaces. These debonded fibres contain little matrix on the surface, and the imprints left in the matrix by the fibres are clearly visible. Matrix microcracking is also visible in matrix-rich areas and in areas where the fibres have been removed. 


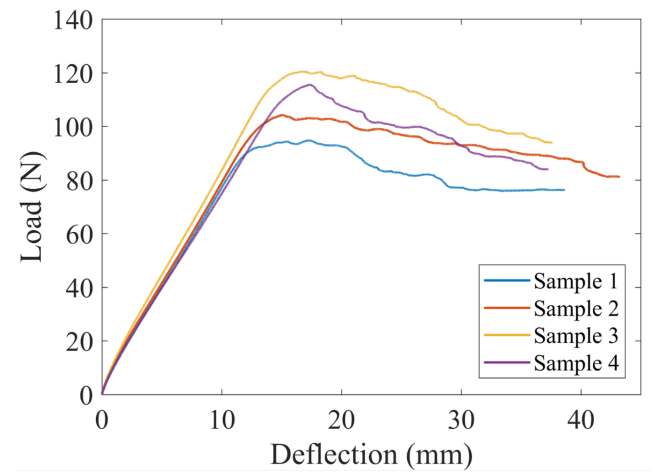

(a)

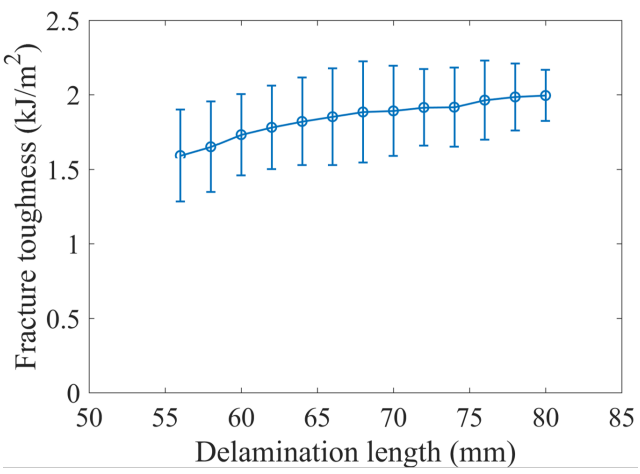

(b)

Figure 11: Mode I interlaminar fracture toughness test curves: (a) load-deflection curves of the crack opening tests and (b) resistance-type fracture behaviour (average and standard deviation values).

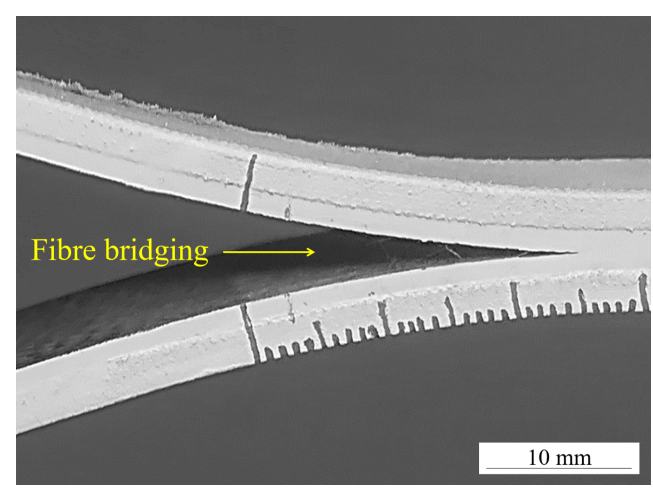

(a)

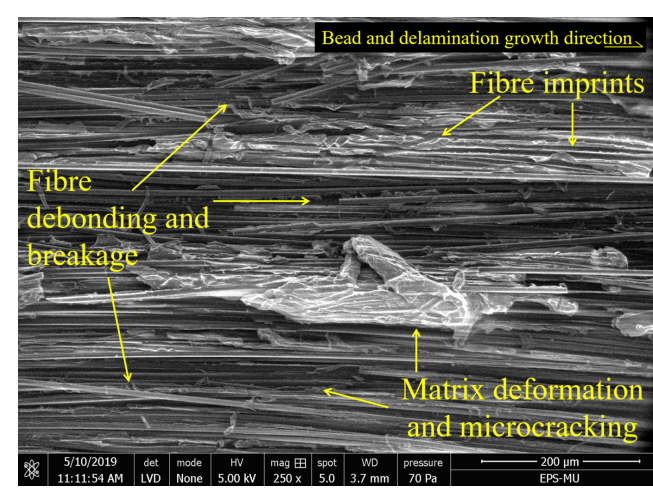

(b)

Figure 12: Mode I interlaminar fracture: (a) fibre bridging and (b) SEM image of the fractured surface. Debonded and fractured fibres, fibre imprints and matrix fracture are visible.

The load-deflection curves for the three validated ENF tests are shown in Figure 13(a) for slightly different crack lengths (value in parentheses). The curves are slightly non-linear and stiffness decreases with the load. The fracture toughness obtained was $1.59(0.33) \mathrm{kJ} / \mathrm{m}^{2}$, and was calculated using the compliance calibration method as described by ASTM D7905 [45]. As in mode I, the fracture surface is very irregular, and debonded and fractured fibres, fibre imprints and matrix deformation and microcracking are observed 
(Figure 13(b)). Fracture toughness in mode II was lower than in mode I. This behaviour is not usual, and may be due to the type of structure of the material that does not favour the interlaminar shear microcracking mode of the matrix in mode II.

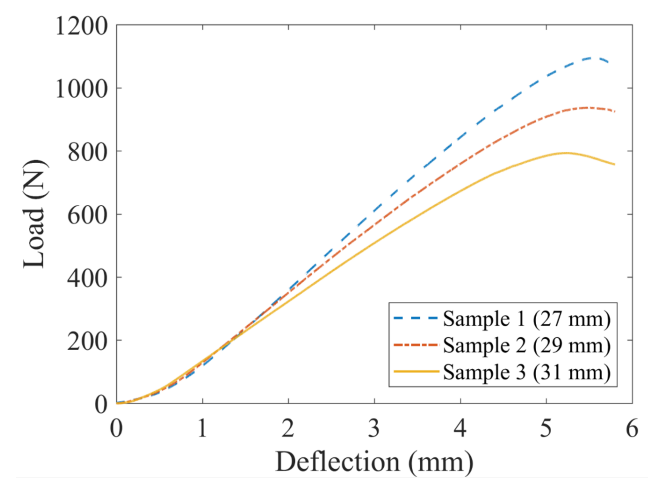

(a)

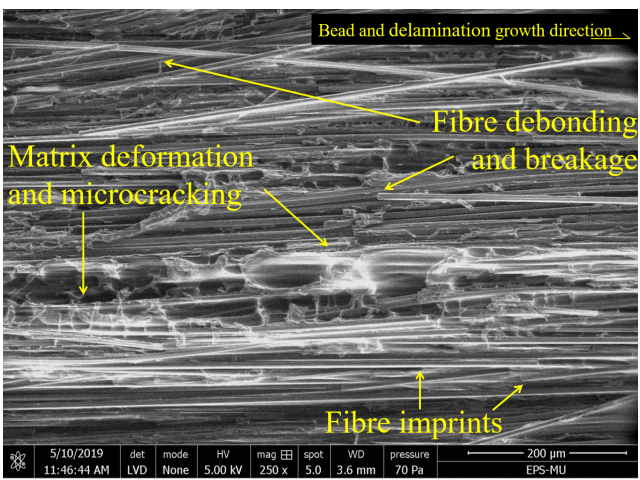

(b)

Figure 13: Mode II interlaminar fracture test: (a) load-deflection curves of the ENF test for slightly different crack lengths (value in parentheses) and (b) SEM image of the fractured surface. Debonded and fractured fibres, fibre imprints and matrix fracture are visible.

\section{Discussion}

As mentioned in the introduction, several studies have addressed the mechanical characterisation of the printed $\mathrm{CCF} / \mathrm{PA}$ in recent years. Most of these works have characterised the properties of the laminate obtained directly from the print, which includes contours and outer layers of nonreinforced PA6 material, and not the lamina properties of the printed CCF/PA. With regards to the longitudinal tensile behaviour, the stiffening effect on the stress-strain curve and the longitudinal splitting fracture mode shown in the present paper were also reported in the literature [15-17]. For longitudinal compression, failure mechanisms similar to those obtained in the present work were reported in [19]. In the aforementioned works, the mechanical properties of the printed laminate were obtained rather than those of the CCF/PA lamina. This justifies that the reported stiffness and strength properties are lower than those presented in this work. The elastic properties of the lamina $E_{1}^{\mathrm{t}}, E_{2}^{\mathrm{t}}$ and $G_{12}$ were investigated in [20]. The reported values are higher than those measured in the present paper: $8 \%$ in $E_{1}^{\mathrm{t}}, 24 \%$ in $G_{12}$ and $57 \%$ in $E_{2}^{\mathrm{t}}$. Significantly thinner specimens were tested in that 
work [20], resulting in a lower ratio of reinforced to non-reinforced layers. Moreover, a lower modulus of elasticity for the PA6 of the outer layers was considered for the determination of the $\mathrm{CCF} / \mathrm{PA}$ lamina properties. These reasons may be behind the differences in property values obtained in the two studies. Finally, with respect to interlaminar behaviour, slightly lower $(6 \%)$ interlaminar shear strength values was reported in [21].

In order to assess the performance of the printed CCF/PA composite, the mechanical properties obtained in the current work were compared with those of an equivalent (reference) material manufactured by means of Hot Compression Moulding (HCM) [29-32]. The reference properties are shown in Table 3 along with those characterised in this study. The tensile mechanical properties in longitudinal direction are similar to the values reported for samples made by HCM [31]. However, for the remaining deformation modes, especially for transverse loading, the properties are significantly lower. This outcome is likely be due to the influence of defects induced by the 3D-printing process which ought to have a larger impact on resin dominated properties. 
Table 3: Mechanical properties of the 3D-printed CCF/PA and comparative with properties obtained by hot compression moulding reference process [30-32] (the standard deviation is indicated in parentheses).

\begin{tabular}{llcc}
\hline Test & Property & Measurement & Reference \\
\hline Longitudinal tension & Tensile modulus (GPa) & $69.4(0.2)$ & $72.2[31]$ \\
& Poisson's ratio & $0.41(0.01)$ & - \\
& Tensile strength (MPa) & $905.3(4.3)$ & $1047[31]$ \\
& Ultimate tensile strain (\%) & $1.27(0.04)$ & - \\
Longitudinal compression & Compressive modulus (GPa) & $63.9(1.3)$ & - \\
& Compressive strength (MPa) & $426.0(9.7)$ & - \\
& Ultimate compression strain (\%) & $0.69(0.02)$ & - \\
\hline Transversal tension & Tensile modulus (GPa) & $3.5(0.1)$ & $7.4[31]$ \\
& Tensile strength (MPa) & $17.9(1.7)$ & $33.3[31]$ \\
& Ultimate tensile strain (\%) & $0.58(0.07)$ & - \\
Transversal compression & Compressive modulus (GPa) & $3.7(0.2)$ & - \\
& Compressive strength (MPa) & $66.0(6.6)$ & - \\
\hline In-plane shear & Shear modulus (GPa) & $1.9(0.1)$ & - \\
& Shear strength at 5\% (MPa) & $43.4(2.6)$ & - \\
& Shear strength at 25\% (MPa) & $61.5(2.0)$ & - \\
\hline Interlaminar shear & Interlaminar shear strength $(\mathrm{MPa})$ & $34.1(0.1)$ & $46.7[30]$ \\
Interlaminar fracture & Mode I fracture toughness $\left(\mathrm{kJ} / \mathrm{m}^{2}\right)$ & $2.00(0.17)$ & $2.20[32]$ \\
& Mode II fracture toughness (kJ/m²) & $1.59(0.33)$ & $2.68[32]$ \\
\hline
\end{tabular}

The mechanical performance of the printed material depends largely on the quality of the bonding between the printed beads. Two phenomena occur in the bead bonding process: the creation and growth of the contact surface between beads, and the molecular diffusion of the polymer chains into the contact surface. Both phenomena depend on the thermal history of the material. The longer the material remains above the glass transition temperature $T_{\mathrm{g}}$, the greater the molecular diffusion between the beads. Part design, process parameters and heat transfer conditions in the material and in the printing chamber directly influence the temperature history [4, 49].

In this study, the composite was extruded at a temperature of $252^{\circ} \mathrm{C}$ while the $T_{\mathrm{g}}$ of the amorphous PA $6 / 3 \mathrm{~T}$ matrix is $143^{\circ} \mathrm{C}$, as determined in [35]. In order to analyse the thermal history of the printed $\mathrm{CCF} / \mathrm{PA}$, the temperature of the material was measured during printing of a $40 \mathrm{~mm}$ long unidirectional sample. An infrared camera (FLIR Titanium $550 \mathrm{M}$ ) was used 
for this purpose. The emissivity was adjusted to 0.75 taking into account the extrusion temperature of the material in the nozzle. It was observed that the recently printed bead cooled very quickly to a temperature below the $T_{\mathrm{g}}$, in approximately one second (Figures 14(a) and 14(b)). In the region where the material was being deposited, at least the three layers underneath exceeded $T_{\mathrm{g}}$. The temperature of the deposited material tended to stabilise at a temperature slightly above $50^{\circ} \mathrm{C}$ (Figure $14(\mathrm{~b})$ ) and the temperature in the printing chamber was stabilised at $28^{\circ} \mathrm{C}$, for an outside room temperature of $19^{\circ} \mathrm{C}$.

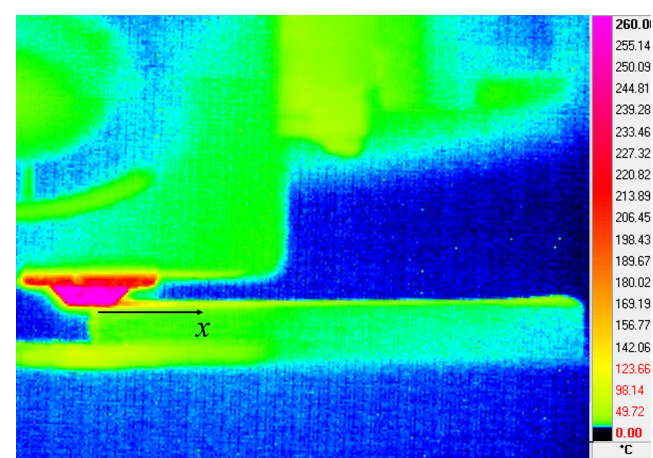

(a)

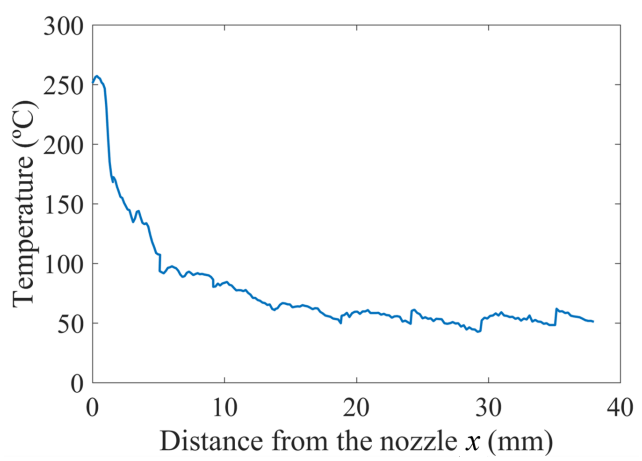

(b)

Figure 14: Thermal history of printed $\mathrm{CCF} / \mathrm{PA}$ composite: (a) temperature distribution after printing a $40 \mathrm{~mm}$ bead and (b) temperature along the deposited bead for the same instant.

From the information above, it would seem that the deposited material heats the bottom layer sufficiently. However, cooling is rather fast and leads to the halting of molecular diffusion within a very short period of time, effectively not allowing for a proper consolidation of the bonding between layers. As a result, ply interfaces become weak regions in the laminates produced the by FFF of continuously reinforced materials. Presumably the prefixed

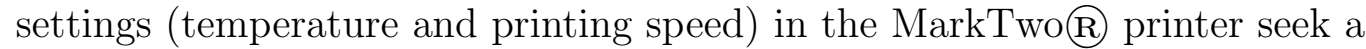
compromise between the mechanical performance of the printed material and the productive capacity of the printer. Similar conclusions were derived in [50], where the temperature and strain history of the printed CCF/PA were measured by sensors embedded in the material. The study also concluded that the fibre orientation strongly influences the process-generated temperature histories and residual strains. In contrast, in HCM, the creation of the interfaces and the diffusion of the material is ensured since the material is 
kept under high pressure levels at temperatures above $T_{\mathrm{g}}$ for a long period of time $\left(280^{\circ} \mathrm{C}\right.$ for 3.5 min under a compression pressure of $4 \mathrm{~kg} / \mathrm{cm}^{2}$ for CF/PA6 pre-impregnated sheets [31]).

The microstructure of the printed parts was also analysed to evaluate the quality of the material and to identify process-induced defects. For this purpose, a unidirectional $\mathrm{CCF} / \mathrm{PA}$ composite sample was printed, and the cross-section was examined by optical microscopy (Leica DM i8C). The microscope images of the cross section of the unidirectional sample are shown in Figure 15 at different magnification levels. The interlayer limits are visible (marked with horizontal dashed lines on Figures 15(a) and 15(b)). This may be an indication that the molecular diffusion of the matrix is in fact incomplete during the printing process. The interface between the adjacent beads are also identifiable (marked with vertical dashed lines on Figure 15(a)), due to the presence of large voids. This observation was also made in $[16,17]$, wherein the overlapping of the beads was identified. In addition, this overlap is not uniform, and limits of beads are alternated with more or less voids (Figure 15(a)). This large number of voids may indicate that the printing process is unable to adequately compact the extruded filament onto the printed part. It can also be observed that the fibre distribution is non-uniform, and both large matrix-dominated and high fibre density zones can be distinguished (Figure 15(b)). This phenomenon was also identified in the pre-printed filament [35].

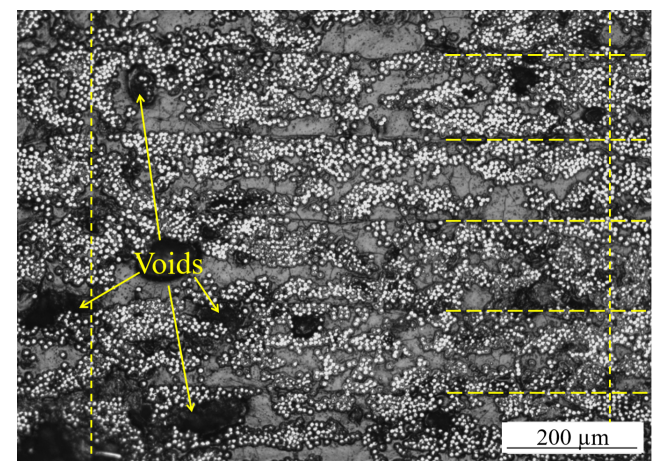

(a)

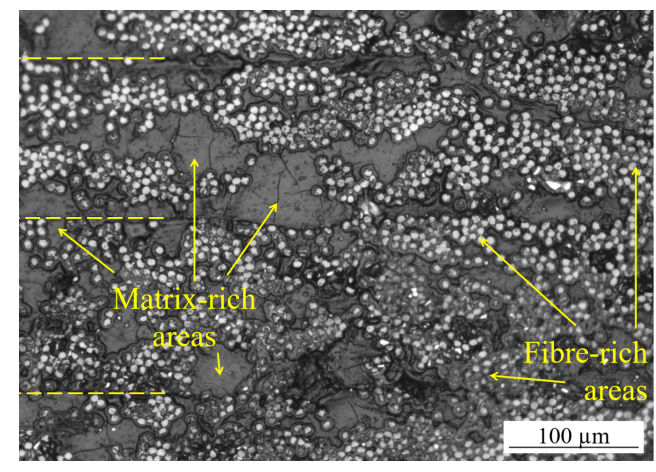

(b)

Figure 15: Cross section of the unidirectional CCF/PA sample at different magnification levels: (a) bead limit regions (vertical dashed lines), interlayer limits (horizontal dashed lines) and voids; and (b) interlayer limits (horizontal dashed lines) and alternated matrixrich and fibre-rich regions. 
The fibre volume fraction obtained with 3D-printing of continuously reinforced laminates (31.4\% reported in section 2.1) is lower than fibre volume fractions obtained with traditional processes. Naturally, the amount of fibre in the printed sample is limited by the amount of fibre in the filament (33.9\% [35]). The insufficient compaction of the material, mainly between the beads, seems to be the origin of the large quantity of voids of the printed parts (7.5\% reported in section 2.1). These values are far from those that can be obtained through the HCM process. A fibre volume fraction of up to $60 \%$ and a void content of less than $1 \%$ were obtained for a hot compressed $\mathrm{CCF} / \mathrm{PA} 6$ material in another study [29].

These process-induced defects have a great influence on the mechanical behaviour of the laminated material. First, the high degree of in-homogeneity of the material may be the cause of the early fracture under transverse tension due to the high stress concentrations that are produced in the matrix near manufacturing defects, such as voids and regions with high fibre density. As shown in Table 3, the transverse tensile mechanical properties are approximately half of those obtained through the HCM process [31]. Second, the weak interlayer bonding makes the interlaminar strength of the printed samples $27 \%$ lower (Table 3) than that obtained by HCM with a lower fibre volume fraction [30]. In addition, the low interlaminar adhesion together with the high compliance of the composite in transverse direction may facilitate the micro-buckling of the layers under compression loading. Finally, the non-homogeneous structure of the material in the interlayer does not excessively penalise the fracture toughness in mode I (the toughness is $91 \%$ of that obtained by HCM [32]). This may be due to the large number of fibre bridges that are created between the fractured faces. In Mode II, however, it seems that the most effective matrix shearing fracture mode is not activated in the fractured surface, and the fracture toughness is significantly affected (59\% of that obtained by HCM [32]).

\section{Concluding remarks}

In this research, the mechanical behaviour of the printed CCF/PA composite has been investigated, as well as the influence of defects and manufacturing limitations on this behaviour. The mechanical performance in longitudinal direction is equivalent to that obtained through the HCM reference process. However, under transverse and interlaminar loads (normal and shear), the mechanical response is strongly influenced by manufacturing 
defects, and the mechanical properties result to be significantly lower than those obtained through HCM. Defects such as a large number of voids, nonhomogeneous distribution of fibres and poor bonding between beads and layers were identified. These defects may be the result of the insufficient thermo-mechanical consolidation of the material during the printing process which occurs due to the fast cooling of the printed material bellow the glass transition temperature.

It is clear from these results, that this process needs further development to be considered viable for high-performance structural applications. In this respect, different improvements are currently being implemented in the process for the reduction of defects and limitations: material preheating systems [51], layer post-compacting systems [52], multi-axis 3D-printing [53] and simultaneous extrusion of different filaments [54].

Despite the limitations identified in the current process, the mechanical characterisation carried out in this study will allow structural components to be designed using advanced simulation techniques and explore the capacity of this emerging technology for the design of lightweight structural components.

\section{Acknowledgments}

This work was supported by the Spanish Ministry of Science, Innovation and Universities (MCIU), the Spanish state Research Agency (AEI) and the European Regional Development Fund (FEDER) [RTI2018-094435-B-C31]; the Spanish Ministry of Economy and Competitiveness [MAT2015-69491C03-02,RYC-2013-14271]; the Autonomous Community of Madrid [PEJD2017-POST/IND-4401]; and the Basque Government [IBA PI2017-49-GVP7, KK-2018/00115].

\section{References}

[1] P. Parandoush, D. Lin, A review on additive manufacturing of polymer-fiber composites, Composite Structures 182 (2017) 36-53. doi:10.1016/j.compstruct.2017.08.088.

[2] G. D. Goh, Y. L. Yap, S. Agarwala, W. Y. Yeong, Recent progress in additive manufacturing of fiber reinforced polymer composite, Advanced Materials Technologies (2018). doi:10.1002/admt.201800271. 
[3] X. Wang, M. Jiang, Z. Zhou, J. Gou, D. Hui, 3D printing of polymer matrix composites: A review and prospective, Composites Part B: Engineering 110 (2017) 442-458. doi:10.1016/j.compositesb.2016.11.034.

[4] B. Brenken, E. Barocio, A. Favaloro, V. Kunc, R. B. Pipes, Fused Filament Fabrication of Fiber-Reinforced Polymers: A Review, Additive Manufacturing 21 (2018) 1-16. doi:10.1016/j.addma.2018.01.002.

[5] H. Qingxi, D. Yongchao, Z. Haiguang, L. Dali, Y. Biao, P. Fujun, Manufacturing and 3D printing of continuous carbon fiber prepreg filament, Journal of Materials Science 53 (2018) 1887-1898. doi:10.1007/s10853017-1624-2.

[6] R. Matsuzaki, M. Ueda, M. Namiki, T. K. Jeong, H. Asahara, K. Horiguchi, T. Nakamura, A. Todoroki, Y. Hirano, Three-dimensional printing of continuous-fiber composites by in-nozzle impregnation, Scientific Reports 6 (2016). doi:10.1038/srep23058.

[7] X. Tian, T. Liu, C. Yang, Q. Wang, D. Li, Interface and performance of 3D printed continuous carbon fiber reinforced PLA composites, Composites Part A: Applied Science and Manufacturing 88 (2016) 198-205. doi:10.1016/j.compositesa.2016.05.032.

[8] Z. Gürdal, R. Olmedo, In-plane response of laminates with spatially varying fiber orientations - Variable stiffness concept, AIAA Journal 31 (1993) 751-758. doi:10.2514/3.11613.

[9] C. S. Lopes, P. P. Camanho, Z. Gürdal, B. F. Tatting, Progressive failure analysis of tow-placed, variable-stiffness composite panels, International Journal of Solids and Structures 44 (2007) 8493-8516. doi:10.1016/j.ijsolstr.2007.06.029.

[10] C. S. Lopes, Z. Gürdal, P. P. Camanho, Variable-stiffness composite panels: Buckling and first-ply failure improvements over straightfibre laminates, Computers and Structures 86 (2008) 897-907. doi:10.1016/j.compstruc.2007.04.016.

[11] C. S. Lopes, Z. Gürdal, P. P. Camanho, Tailoring for strength of composite steered-fibre panels with cutouts, Composites Part A: Applied Science and Manufacturing 41 (2010) 1760-1767. doi:10.1016/j.compositesa.2010.08.011. 
[12] L. Pyl, K. A. Kalteremidou, D. Van Hemelrijck, Exploration of the design freedom of 3D printed continuous fibre-reinforced polymers in open-hole tensile strength tests, Composites Science and Technology 171 (2019) 135-151. doi:10.1016/j.compscitech.2018.12.021.

[13] H. Zhang, D. Yang, Y. Sheng, Performance-driven 3D printing of continuous curved carbon fibre reinforced polymer composites: A preliminary numerical study, Composites Part B: Engineering 151 (2018) 256-264. doi:10.1016/j.compositesb.2018.06.017.

[14] A. A. Safonov, 3D topology optimization of continuous fiber-reinforced structures via natural evolution method, Composite Structures 215 (2019) 289-297. doi:10.1016/j.compstruct.2019.02.063.

[15] L. G. Blok, M. L. Longana, H. Yu, B. K. S. Woods, An investigation into 3D printing of fibre reinforced thermoplastic composites, Additive Manufacturing 22 (2018) 176-186. doi:10.1016/j.addma.2018.04.039.

[16] G. D. Goh, V. Dikshit, A. P. Nagalingam, G. L. Goh, S. Agarwala, S. L. Sing, J. Wei, W. Y. Yeong, Characterization of mechanical properties and fracture mode of additively manufactured carbon fiber and glass fiber reinforced thermoplastics, Materials and Design 137 (2018) 79-89. doi:10.1016/j.matdes.2017.10.021.

[17] G. Chabaud, M. Castro, C. Denoual, A. Le Duigou, Hygromechanical properties of 3D printed continuous carbon and glass fibre reinforced polyamide composites for outdoor structural applications, Additive Manufacturing 26 (2018) 94-105. doi:10.1016/j.addma.2019.01.005.

[18] F. Van Der Klift, Y. Koga, A. Todoroki, M. Ueda, Y. Hirano, R. Matsuzaki, 3D printing of continuous carbon fibre reinforced thermo-plastic (CFRTP) tensile test specimens, Open Journal of Composite Materials 06 (2016) 18-27. doi:10.4236/ojcm.2016.61003.

[19] J. Justo, L. Távara, L. García-Guzmán, F. París, Characterization of 3D printed long fibre reinforced composites, Composite Structures 185 (2018) 537-548. doi:10.1016/j.compstruct.2017.11.052.

[20] T. A. Dutra, R. T. L. Ferreira, H. B. Resende, A. Guimarães, Mechanical characterization and asymptotic homogenization of 3D-printed 
continuous carbon fiber-reinforced thermoplastic, Journal of the Brazilian Society of Mechanical Sciences and Engineering 41 (2019) 133. doi:10.1007/s40430-019-1630-1.

[21] M. A. Caminero, J. M. Chacón, J. M. Reverte, Interlaminar bonding performance of 3D printed continuous fibre reinforced thermoplastic composites using fused deposition modelling, Polymer Testing 68 (2018) 415-423. doi:10.1016/j.polymertesting.2018.04.038.

[22] A. N. Dickson, J. N. Barry, K. A. McDonnell, D. P. Dowling, Fabrication of continuous carbon, glass and Kevlar fibre reinforced polymer composites using additive manufacturing, Additive Manufacturing 16 (2017) 146-152. doi:10.1016/j.addma.2017.06.004.

[23] M. Araya-Calvo, I. López-Gómez, N. Chamberlain-Simon, J. L. LeónSalazar, T. Guillén-Girón, J. S. Corrales-Cordero, O. Sánchez-Brenes, Evaluation of compressive and flexural properties of continuous fiber fabrication additive manufacturing technology, Additive Manufacturing 22 (2018) 157-164. doi:10.1016/j.addma.2018.05.007.

[24] J. Naranjo-Lozada, H. Ahuett-Garza, P. Orta-Castañón, W. M. H. Verbeeten, D. Sáiz-González, Tensile properties and failure behavior of chopped and continuous carbon fiber composites produced by Additive Manufacturing, Additive Manufacturing 26 (2019) 227-241. doi:10.1016/j.addma.2018.12.020.

[25] H. Mei, Z. Ali, I. Ali, L. Cheng, Tailoring strength and modulus by $3 \mathrm{D}$ printing different continuous fibers and filled structures into composites, Advanced Composites and Hybrid Materials (2019) 1-8. doi:10.1007/s42114-019-00087-7.

[26] M. Mohammadizadeh, I. Fidan, M. Allen, A. Imeri, Creep behavior analysis of additively manufactured fiber-reinforced components, International Journal of Advanced Manufacturing Technology 99 (2018) 1225-1234. doi:10.1007/s00170-018-2539-z.

[27] A. Imeri, I. Fidan, M. Allen, D. A. Wilson, S. Canfield, Fatigue analysis of the fiber reinforced additively manufactured objects, Open Journal of Composite Materials 98 (2018) 2717-2724. doi:10.1007/s00170-018$2398-7$. 
[28] M. A. Caminero, J. M. Chacón, I. Garcia-Moreno, G. P. Rodriguez, Impact damage resistance of 3D printed continuous fibre reinforced thermoplastic composites using fused deposition modelling, Composites Part B: Engineering 148 (2018) 93-103. doi:10.1016/j.compositesb.2018.04.054.

[29] E. C. Botelho, L. Figiel, M. C. Rezende, B. Lauke, Mechanical behavior of carbon fiber reinforced polyamide composites, Composites Science and Technology 63 (2003) 1843-1855. doi:10.1016/S0266-3538(03)001192 .

[30] J. W. Yi, W. Lee, D. G. Seong, H. J. Won, S. W. Kim, M. K. Um, J. H. Byun, Effect of phenoxy-based coating resin for reinforcing pitch carbon fibers on the interlaminar shear strength of PA6 composites, Composites Part A: Applied Science and Manufacturing 87 (2016) 212219. doi:10.1016/j.compositesa.2016.04.028.

[31] Y. Ma, M. Ueda, T. Yokozeki, T. Sugahara, Y. Yang, H. Hamada, A comparative study of the mechanical properties and failure behavior of carbon fiber/epoxy and carbon fiber/polyamide 6 unidirectional composites, Composite Structures 160 (2017) 89-99. doi:10.1016/j.compstruct.2016.10.037.

[32] J. P. Reis, M. F. S. F. de Moura, R. D. F. Moreira, F. G. A. Silva, Pure mode I and II interlaminar fracture characterization of carbonfibre reinforced polyamide composite, Composites Part B: Engineering 169 (2019) 126-132. doi:10.1016/j.compositesb.2019.03.069.

[33] G. T. Mark, A. S. Gozdz, Apparatus for fiber reinforced additive manufacturing, 2014. US 2014/0328963 A1.

[34] S. S. Yao, F. L. Jin, K. Y. Rhee, D. Hui, S. J. Park, Recent advances in carbon-fiber-reinforced thermoplastic composites: A review, Composites Part B: Engineering 142 (2018) 241-250. doi:10.1016/j.compositesb.2017.12.007.

[35] C. Pascual-González, M. Iragi, A. Fernández, L. Aretxabaleta, C. S. Lopes, A methodology to analyse the factors behind the mechanical response of 3D-printed composites, Composites Part B: Engineering (Unpublished results - Under review). 
[36] ASTM International, ASTM D3171-15: Standard Test Methods for Constituent Content of Composite Materials, 2015. doi:10.1520/D3171-15.

[37] ASTM International, ASTM D792-13: Standard Test Methods for Density and Specific Gravity (Relative Density) of Plastics by Displacement, 2013. doi:10.1520/D0792-13.

[38] J. Brandrup, E. H. Immergut, E. A. Grulke, A. Abe, D. R. Bloch, Polymer handbook, volume 7, Wiley New York etc, 1989.

[39] Toray Composite Materials America, Inc., T300 standard modulus carbon fiber Rev. 6, Updated April 13, 2018. URL: https://www. toraycma. com.

[40] ASTM International, ASTM D3039/D3039M-17: Standard Test Method for Tensile Properties of Polymer Matrix Composite Materials, 2017. doi:10.1520/D3039_D3039M-17.

[41] ASTM International, ASTM D3410/D3410M-16: Standard Test Method for Compressive Properties of Polymer Matrix Composite Materials with Unsupported Gage Section by Shear Loading, 2016. doi:10.1520/D3410_D3410M-16.

[42] ASTM International, ASTM D3518/D3518M-18: Standard Test Method for In-Plane Shear Response of Polymer Matrix Composite Materials by Tensile Test of a \pm 45 Laminate, 2018. doi:10.1520/D3518_D3518M-18.

[43] ASTM International, ASTM D2344/D2344M-16: Standard Test Method for Short-Beam Strength of Polymer Matrix Composite Materials and Their Laminates, 2016. doi:10.1520/D2344_D2344M-16.

[44] ASTM International, ASTM D5528-13: Standard Test Method for Mode I Interlaminar Fracture Toughness of Unidirectional Fiber-Reinforced Polymer Matrix Composites, 2013. doi:10.1520/D5528-13.

[45] ASTM International, ASTM D7905/D7905M-14: Standard Test Method for Determination of the Mode II Interlaminar Fracture Toughness of Unidirectional Fiber-Reinforced Polymer Matrix Composites, 2014. doi:10.1520/D7905_D7905M-14. 
[46] D. Young, N. Wetmore, M. Czabaj, Interlayer fracture toughness of additively manufactured unreinforced and carbon-fiber-reinforced acrylonitrile butadiene styrene, Additive Manufacturing 22 (2018) 508-515. doi:10.1016/j.addma.2018.02.010.

[47] F. Naya, M. Herráez, C. S. Lopes, C. González, S. Van der Veen, F. Pons, Computational micromechanics of fiber kinking in unidirectional FRP under different environmental conditions, Composites Science and Technology 144 (2017) 26-35. doi:10.1016/j.compscitech.2017.03.014.

[48] Markforged Inc., Material Datasheet - Rev 3.1, Updated October 5, 2019. URL: https://markforged.com.

[49] Q. Sun, G. M. Rizvi, C. T. Bellehumeur, P. Gu, Effect of processing conditions on the bonding quality of FDM polymer filaments, Rapid Prototyping Journal 14 (2008) 72-80. doi:10.1108/13552540810862028.

[50] C. Kousiatza, D. Tzetzis, D. Karalekas, In-situ characterization of 3D printed continuous fiber reinforced composites: A methodological study using fiber Bragg grating sensors, Composites Science and Technology 174 (2019) 134-141. doi:10.1016/j.compscitech.2019.02.008.

[51] V. Kishore, C. Ajinjeru, A. Nycz, B. Post, J. Lindahl, V. Kunc, C. Duty, Infrared preheating to improve interlayer strength of big area additive manufacturing (BAAM) components, Additive Manufacturing 14 (2017) 7-12. doi:10.1016/j.addma.2016.11.008.

[52] B. Ranabhat, S. Kirmse, K. T. Hsiao, Feasibility Study of Novel Magnetic Compaction Force Assisted Additive Manufacturing (MCFAAM) Methodology for Continuous Carbon Fiber Reinforced Polymer (C-CFRP) Composites, 2019. doi:10.33599/nasampe/s.19.1535.

[53] W. De Backer, M. J. L. van Tooren, A. P. Bergs, Multi-axis multimaterial fused filament fabrication with continuous fiber reinforcement, volume n 210049, 2018. doi:10.2514/6.2018-0091.

[54] M. Yamawaki, Y. Kouno, Fabrication and mechanical characterization of continuous carbon fiber-reinforced thermoplastic using a preform by three-dimensional printing and via hot-press molding, Advanced Composite Materials 27 (2017) 1-11. doi:10.1080/09243046.2017.1368840. 